\title{
De empleados a dueños. Cultura, experiencia(s) y relaciones de alteridad en el proceso de toma y recuperación de una fábrica'
}

Carina Balladares (UBA-UNSAM)

\section{INTRODUCCIÓN}

Con más de 200 casos conocidos, el fenómeno de toma y autogestión ${ }^{2}$ de empresas por parte de sus trabajadores se convirtió en una de las expresiones sociales más sobresalientes del complejo nuevo milenio argentino ${ }^{3}$. Se trata de una experiencia que permite ver, en diversas escalas y dimensiones, cómo las tramas sociales atraviesan un veloz proceso de cambio que involucra a individuos que, lejos de ser objetos pasivos de la metamorfosis macro-estructural, son sujetos activos en el propio contexto de transformación.

El fenómeno de las empresas tomadas y recuperadas ha sido ampliamente investigado 4 . Sin embargo, y aunque se ha escrito de modo abundante sobre las actitudes, identidades y subjetividades de los involucrados en este tipo de procesos ${ }^{5}$, hasta ahora no se ha respondido del todo la siguiente pregunta: ¿cómo se construye y materializa la idea de que tomar y autogestionar una fábrica es una alternativa para trabajadores que por años trabajaron bajo patrón?

En este artículo daremos cuenta de esta pregunta a partir de la descripciónreconstrucción de la 'cultura fabril' $y$, fundamentalmente, de las diversas experiencias de algunos de los obreros que trabajaban en la ex empresa Elenic S.A. y luego formaron parte de la Cooperativa Crispín, que gestiona la fábrica en la actualidad. En nuestro recorrido, analizaremos un fragmento del material empírico recabado en varias etapas entre los años 2004 y 2010 para nuestra tesis doctoral ${ }^{6}$. Puntualmente, en este texto describiremos cómo se organizó una específica 'cultura fabril' durante los años en que los jefes y el patrón eran responsables de organizar la producción, y cómo ella se desenvolvió en el proceso de ocupación, toma e inicios de la nueva situación de autogestión.

Para lograrlo, describiremos ciertos detalles de la historia de la empresa nacional que se convirtió en empresa recuperada; describiremos algunos aspectos 
del estilo organizacional y de las relaciones de clase entre trabajadores y empleadores; veremos, brevemente, cómo se desarrolló el proceso de crisis empresarial; y finalmente haremos foco en la serie de acontecimientos que permitió que la acción de la toma de la fábrica fuera posible, el espacio simbólico que la contextualizó, y los diferentes modos de actuar de los trabajadores implicados en esa compleja trama de transformación. Pero, antes de avanzar, es preciso hacer unas breves anotaciones teóricas.

Ciertas investigaciones que desde América Latina han pensado la dimensión cultural del mundo de los trabajadores (Dias Duarte 1986; Guadarrama 2000; Leite Lopes 1976, 1988) han dado un impulso importante al desarrollo del concepto de 'cultura fabril' que utilizamos en este estudio de caso. Entre ellas, una referencia particularmente significativa es la etnografía que el antropólogo mexicano Luis Reygadas realizó en empresas maquiladoras de Guatemala y México. En su investigación comparativa, elaboró una definición de "cultura del trabajo" que se relaciona de un modo cercano con nuestras nociones. Desde una perspectiva semiótica e histórica, el autor la entiende como un proceso de producción, transmisión y apropiación de significados en contextos históricos y sociales específicos, y la define como "la generación, actualización y transformación de formas simbólicas en la actividad laboral” (Reygadas 2002: 20). En su análisis, remarca "la importancia de entender la creación y apropiación de formas simbólicas en el trabajo como un proceso en el que los agentes actualizan su cultura dentro de contextos y relaciones de poder específicos" (Ibíd.: 20). En este sentido, el concepto de cultura del trabajo "también puede ayudar a entender la dialéctica entre diferenciación e integración de las clases sociales, como un proceso de negociación y lucha que tiene aspectos materiales y simbólicos" (Ibíd.: 296).

En la misma línea teórica, pensamos que es posible analizar el modo en que se forman y transforman las configuraciones culturales de los sujetos que integran el colectivo de trabajadores de la Cooperativa Crispín/ex Elenic, si se parte de una consideración que comprende que la cultura no sofoca lo idiosincrásico, y que los individuos nunca pueden ser reducidos a ella, aunque en parte los constituya. Por lo tanto, llamamos 'cultura fabril', de los trabajadores de Crispín/ex Elenic, al conjunto de configuraciones simbólicas que producen quienes transitaron y transitan la empresa de manera cotidiana. Consideramos que dicha 'cultura fabril', aunque es elástica, no homogénea, flexible y porosa respecto del mundo externo, posee rasgos propios, producto de la interacción 'situada' de los trabajadores en su contexto histórico. A su vez, es fruto de la actividad creativa de estos sujetos, que la reproducen y alteran: la experiencia constituye la cultura y la cultura constituye la experiencia. En este sentido, el análisis que proponemos considera que 'la novedad' (quedar sin trabajo, protagonizar acciones de protesta y reclamo, ocupar y tomar la empresa, comenzar a autogestionar la producción de la fábrica bajo el formato de cooperativa, etc.) es leída por las estructuras simbólicas de los sujetos, que se sirven de ellas como punto de referencia, como pivote desde donde se observa la nueva situación. Pero, a su vez, planteamos que estas estructuras —creadas, sedimentadas e internalizadas en procesos de más larga duración - son objetos históricos y contingentes, que pueden no solo actualizarse sino también transformarse ante la novedad. 


\section{PATRONES Y EMPLEADOS}

\section{I}

Nuestro caso de estudio, la Cooperativa Crispín, es una "fábrica recuperada" por sus trabajadores, que está "bajo gestión obrera" desde fines de 20037. En la actualidad, cuenta con un grupo de 150 asociados, hombres y mujeres de diversas edades cuyas características son heterogéneas. Algunos, trabajaban en la fábrica de Santa Catalina ${ }^{8}$ donde actualmente funciona la cooperativa. Otros, trabajaban en las fábricas de Las Sardinas ${ }^{9}$, que estaban ubicadas a varios kilómetros de distancia de Santa Catalina. También se han sumados a la cooperativa trabajadores nuevos, son hijos - en su mayoría-, familiares y conocidos de ex empleados de la vieja empresa.

La cooperativa se encuentra establecida en el edificio que ocupaba la Planta 1 de la ex firma Elenic S.A., una importante empresa productora de calzado e indumentaria deportiva de Argentina, que poseía, entre otras, la concesión de la marca internacional Brisas. La empresa llegó a tener varias plantas de producción distribuidas en las provincias de Buenos Aires, La Rioja, Córdoba y Corrientes. Según afirmaciones de su ex dueño ${ }^{10}$, Elenic alcanzó a contabilizar cerca de 7200 empleados, facturando alrededor de 320 millones de dólares al año, a inicios de la década de 1990. Varios de sus antiguos empleados afirman haber vivido una cierta bonanza económica, la cual se perdió paulatinamente desde mediados de la década de 1990 hasta llegar a una crisis terminal, hacia fines del año 2001. Ellos señalan como causantes de la debacle la apertura indiscriminada del mercado durante el gobierno de Carlos Menem (que provocó el ingreso masivo de productos deportivos a precios más bajos que los de manufactura local), el Efecto Tequila en 1994"11, la crisis económica del país en general, que la empresa tenía un endeudamiento feroz y errores de gestión cometidos por sus directivos.

El relato compartido indica que en 1953, inicialmente en un galpón pequeño, Don Germán Takopian inició la construcción del imperio Elenic junto a unos pocos empleados ${ }^{12}$. Algunos se convertirían en personas de su confianza y seguirían acompañándolo hasta el final. Luego, Elenic se mudó a otro galpón mayor, donde se fundó la Planta 1. Dicho galpón fue ampliando sus dimensiones hasta transformarse en una gran fábrica de varios pisos, que ocupa tres cuartas partes de una manzana, ubicada cerca del cementerio municipal. De manera paralela, se fueron instalando diferentes plantas productivas y locales de venta al público en diversas localidades de la provincia de Buenos Aires y del interior del país. Es así como, según los relatos, desde los años cincuenta hasta inicios de la década del noventa (cuando comenzó la crisis) Elenic creció de manera sostenida, aumentando su cantidad de empleados, nivel tecnológico, volumen de negocios, volumen de ventas, infraestructura, capacidad edilicia y cantidad de unidades productivas.

Resulta importante señalar que, si bien la empresa tenía varias unidades productivas, la Planta 1, el lugar donde funciona la Cooperativa Crispín en la actualidad, era un sitio de alto valor, no tanto en términos de producción, pues había otras plantas más importantes que esa, sino en términos afectivos (era la empresa donde "comenzó todo", la "nave insignia" de Elenic, según el viejo industrial) y también en términos administrativos. 
Alrededor de la manzana donde se emplazaba la Planta 1, se construyeron diferentes edificaciones. Rodeando la fábrica se podían ver galpones para guardar insumos y mercancías, un gran local de venta de calzados y ropa deportiva, y una guardería y jardín maternal, donde personal especializado cuidaba a los hijos de los trabajadores de la empresa. En la cuadra que enfrenta a la entrada principal de la fábrica había un edificio con oficinas. Era la administración central de Elenic, sitio donde se desarrollaban las reuniones de directorio, lugar donde se hallaba el despacho de Don Germán Takopian y centro de circulación de la familia fundadora.

Takopian era un hijo de inmigrantes armenios que tenía una gran llegada a muchos ex empleados de su empresa. Era considerado un hombre emprendedor, vivo y creativo, incluso por los trabajadores que sentían más distancia respecto de él. Don Germán era definido como una persona que se había hecho de abajo. Él“...era un industrial...", un "...empresario nacional..." ${ }^{13}$. Él era "otra cosa". No era como su hijo menor (ejecutor de los despidos en masa de cientos de trabajadores en el año 2001), o como parte de su entorno (empleados que cobraban mucho y no sabían cómo hacer una zapatilla o cómo administrar bien una empresa). Él sabía trabajar codo a codo con los operarios, así lo había hecho en los inicios. Así, trabajando mucho, construyó Elenic.

[En los primeros años, la empresa fabricaba unos zapatos que se vendían muy bien...] "Se hacían 120 pares por día. La suela era por moldeo. La mezcla la hacía yo de noche en la fábrica (...) Aquello en los primeros tiempos era duro: se incorporaba el negro humo al caucho. El aire era irrespirable. Pero lo tenía que respirar. Me manchaba y precisaba no sé qué tiempo para bañarme. Pasaba semanas escupiendo el negro del humo (...) Yo salía de ahí y me tenía que ir en bicicleta a casa porque no podía ir en colectivo, parecía un deshollinador. Volvía a mi casa a las dos de la mañana luego de media hora de bicicleta. Y a bañarme, una ducha de media hora para sacarme y sacarme tanto negro de humo..."14.

Amante del fútbol, Takopian supo codearse con jugadores del circuito local e internacional, también con periodistas e importantes figuras del mundo deportivo en general. El hecho de que la marca más importante de la empresa, Brisas, fuera sponsor de la selección nacional de fútbol, y que en la planta se fabricaran las zapatillas y la ropa deportiva que luego usaban los grandes jugadores argentinos del mundial, constituía parte de los elementos que conformaban la 'cultura fabril' de los trabajadores de la ex Elenic. Si bien la marca Brisas es trasnacional y en Argentina era fabricada por Elenic en virtud de un acuerdo comercial que le otorgaba ese derecho, ella constituía, en parte, una suerte de marca nacional (BRISAS-ELENIC), positivamente vinculada con ideas de 'argentinidad' para una buena parte de los trabajadores. Así ser obrero de Elenic generaba un sentimiento de pertenencia positivo. Esto se vinculaba también a los ritmos de los mundiales de fútbol (sobre todo en la década 1980 e inicio de 1990), donde se incrementaba la producción de ropa deportiva. Así lo ilustra el testimonio de El Loco Flores:

“Salían botines, salían camisetas, y la gente los usaba. Teníamos mucho más trabajo, le hacíamos la ropa a la selección, ¿viste? Ahí me di el gusto de hacer los botines para la selección, y las zapatillas que usaban los jugadores... La vida mía en esa época era buena". 
Takopian también organizó un equipo de fútbol propio, el Equipo de las Estrellas, donde él mismo se desempeñaba como jugador junto con algunos trabajadores de la empresa y ciertos futbolistas renombrados ya retirados, como Amadeo Carrizo. Pero, aunque el gusto por el fútbol era compartido entre el patrón y muchos de los operarios de Elenic, y aunque el Equipo de las Estrellas tenía entre sus miembros a algunos trabajadores, este se diferenciaba de los equipos que armaban los obreros de planta ${ }^{15}$.

Don Germán, un hombre que se definía a sí mismo como laburante ${ }^{16}$, ejercía un liderazgo empresario, caracterizado por el trato directo con los trabajadores. Como persona sencilla, pero de dinero, tenía actitudes generosas frente a problemas puntuales de sus empleados. Por ejemplo, en ciertas ocasiones, prestó sumas de dinero que los trabajadores devolvían en cuotas. A Ignacio, un hombre de 72 años que hoy día trabaja en la empresa recuperada como portero, le dio la casita donde actualmente vive ${ }^{17}$. A Morán, un técnico electromecánico de 68 años, le regaló un dinero que, en su momento, le permitió terminar de comprar su casa. A "la Pantera" Sosa, un operario de más de 60 años que, además, era miembro de "El Equipo de Las Estrellas", le regaló un auto. Al Loco Flores, un ex supervisor de línea de 46 años, también le regaló dinero para que comprara su casa.

La acción generosa producía un vínculo basado en expectativas mutuas de intercambio (Mauss 1979). En ese contexto desigual y jerárquico, los favores tenían carácter de acción ejemplar: no todos los empleados obtuvieron un préstamo o regalo de Don Germán, sin embargo varios de ellos sabían —o suponían- que si necesitaban algo podían pedírselo. Y este saber - o suponer - se convirtió en un lazo con la empresa, fue uno de los elementos que contribuyó a crear la sensación de pertenencia a una comunidad de tipo familiar. Este trato amable y directo fue experimentado con mayor intensidad entre los trabajadores de la Planta 1 de Santa Catalina y entre los más viejos, pues a medida en que la empresa fue aumentando su tamaño y cantidad de empleados las relaciones personalizadas patrón-empleado se hacían menos cotidianas. Aun así, dos ex empleadas de la fábrica (María y Georgina) me comentaron que, ya para fines de la década de 1980 e inicios de 1990, en alguna ocasión vieron a Don Germán caminando por la fábrica y no dudaron en acercarse a él a pedirle trabajo para un familiar. En esas ocasiones, Takopian tuvo en cuenta los pedidos y las personas en cuestión ingresaron a la empresa.

Al mismo tiempo, como dueño de la empresa, Takopian se preocupaba por el bienestar de sus operarios en general. A veces con pequeños gestos simbólicos, como regalar un pan dulce a cada operario para navidad. Otras veces, con acciones de mayor envergadura, como la de construir una guardería y jardín maternal modelo en la misma cuadra de la Planta 1, donde profesionales especialmente formadas cuidaban a los hijos de los trabajadores de la empresa. Allí asistían desde bebés en período de lactancia (que eran amamantados por sus propias madres, gracias a un permiso especial que se les otorgaba para salir de la línea de producción por un rato, y acudir a alimentar a sus niños) hasta pequeños de cinco años de edad. Se trata de acciones paternalistas que en su modo de establecer una "continuidad entre trabajo y vida" (Sierra Álvarez 1990: 4) permiten comprender, en parte, la centralidad que la figura de dicho empresario tenía entre muchos trabajadores de la fábrica aún varios años después de la recuperación ${ }^{18}$. 
De este modo, el dueño y fundador de la empresa, que tenía manos de trabajador y "conocía muy bien el oficio del calzado", se había ganado el respeto, la fidelidad y el afecto de buena parte de sus empleados. Así lo relataba el Loco Flores, un ex supervisor de línea de Planta 1, que se convirtió en líder del grupo de los trabajadores que desarrolló el proceso de lucha cuando fueron despedidos de manera masiva y, también, ex presidente de la cooperativa ${ }^{19}$ :

Loco Flores: Yo tenía muy buena relación con el dueño, bah, el dueño en realidad con los que trabajaban tenía una buena relación (...) y y él venía y nos veía, y hablábamos... siempre intercambiábamos palabras y todo... y después un día... [Hace una pausa]... me preguntó si estaba alquilando. Yo le dije que estaba alquilando y ahorrando, que la intención mía era, poder comprar mi casa. Y él me dijo: “¿cuánto necesitas?, yo le dije "cuatro mil dólares". iLe podría haber dicho veinte mil dólares que me los hubiese dado!

Carina: ¿Te los dio así en mano?

Loco Flores: Sí, me los dio. Me dijo: "vení mañana". iNo me olvido más! Fui al día siguiente y me dijo: "tomá, te lo regalo".

Carina: Y vos, ¿Qué sentiste?

Loco Flores: No, no. Yo a Germán Takopian le tengo mucho respeto..., le fui fiel. En eso yo..., así como hoy estoy al frente de todo esto..., él me conoce y sabe que yo fui fiel. Pero... [el Loco hace una pausa], llegó un momento en que era mucho el desgaste, y acá estamos, con los compañeros, comprometidos en este nuevo proceso.

Ahora bien, es importante señalar que los sentimientos de fidelidad no eran totalmente homogéneos ni estaban exentos de tensiones contradictorias. Siempre hubo críticas al modo en que se organizaba la empresa ${ }^{20}$, aun cuando Don Germán buscó ajustarse al modelo del "buen patrón" (Sigaud 1996). Por otra parte, y en la medida en que comenzaron a sentirse las dificultades económicas, durante la década de 1990, algunos trabajadores comenzaron a acumular resentimientos, una emoción que se manifestaba progresivamente en los inicios de la crisis, con los primeros cimbronazos, o que explotó luego de la debacle final, momento en el que algunos empleados abrieron los ojos. De esta manera, a la hora de hablar del ex dueño, se mezclan la bronca, el cariño y la admiración, el reconocimiento y la rabia, el respeto y la sensación de traición. A lo largo de mi trabajo de campo he visto como estos sentimientos pueden repartirse de manera desigual y ambigua entre los miembros de la cooperativa. Hay extrabajadores que hablan con mucha estima y casi con veneración del viejo industrial, otros lo critican fuertemente y están aquellos que comparten ambas posiciones hacia el fundador de la empresa.

Estos trabajadores no solo perdieron el empleo en la fabrica, también perdieron el dinero en calidad de salarios atrasados y cargas sociales no pagadas, y la indemnización por despido que se les adeudaba. Sin embargo, y aunque muchos consideran que la acumulación de estas deudas es imperdonable, todavía hay quienes siguen manteniendo un cierto cuidado hacia la figura de Takopian. Así, por ejemplo, un día que me encontraba presente en el jardín maternal, en medio de una charla sobre la producción, el Cejas, en ese entonces encargado del diseño de calzados en la cooperativa, expuso su modo de tomar posición frente al problema: "nunca odié a mi Patrón (...), hay gente a la que le decís Takopian y es como si les hablaras del demonio, no nos cagó Takopian, nos cagó el 
sistema", remarcó las últimas palabras con énfasis, diferenciándose así de ciertas voces que eran más reprobatorias respecto de la forma de actuar del viejo industrial.

Ubicado casi en el polo opuesto al del Cejas se encuentra Ferraro, un importante miembro del grupo de operarios que desarrolló el proceso de lucha. Él nunca llegó a participar de esa trama de relaciones personalizadas que hemos descrito más arriba. Cuando se refiere a Takopian, es evidente no solo la existencia de una distancia social o de clase, también hay una distancia afectiva.

En este punto resulta conveniente hacer una pequeña digresión. Para el Cejas, Ferraro era un tipo que se había pasado 20 años haciendo lo mismo. Oponía esta actitud a la suya propia, pues él había querido progresar dentro de la empresa, y lo había logrado. Pasó de operario de línea a asistente en "desarrollo de calzado" en el tiempo en que la fábrica se encontraba bajo patrón, es más, el propio Takopian incentivaba y apoyaba que siguiera estudios terciarios en diseño y modelaje de calzado, cosa que el Cejas hizo ${ }^{21}$.

Ferraro, en cambio, me confirmó que su trabajo no había cambiado mucho desde que había ingresado a la empresa, a los 21 años, en 1985, hasta el momento de los despidos masivos de 2001. Cuando ingresó a la empresa trabajó tres o cuatro años en el preparado de suelas. Luego pasó al área de armado, "prácticamente estuve siempre en el mismo puesto" me comentó en una ocasión. Sin embargo, el sentido que él le da a su propia experiencia dentro de la empresa es diferente del que tenía el Cejas. Ferraro, que militó en un partido de izquierda y llegó a hacer algunas materias de la Carrera de Ciencias Económicas de la UBA, no orientaba sus deseos hacia 'progresar' dentro de la fábrica. Simplemente, no se lo propuso. Pero Ferraro es un sujeto emprendedor, y con capacidades organizativas. Puso en juego estos recursos en el momento del aguante, la ocupación y la toma y, posteriormente, como miembro del Consejo de Administración y como pieza importante en la organización general de la producción dentro de la cooperativa. Sin embardo, durante las épocas de la vieja Elenic sus capacidades no fueron orientadas en un sentido de un 'progreso individual'. En realidad, la diferencia entre estos trabajadores radica en que Ferraro no creía en el 'sistema de premios personalizados' que tenía la empresa. Sistema en el que sí creía el Cejas, pero también el Loco Flores, que había pasado de ser operario a ser uno de los encargados de producción de la fábrica (como supervisor de una de las líneas de armado de calzado), quien, al igual que el Cejas pero a diferencia de Ferraro, tenía un trato personal con Don Germán Takopian.

Vemos así como entre los ex trabajadores de Elenic encontramos, al mismo tiempo, diversas experiencias dentro de la empresa y diversas visiones respecto a la forma de actuar del viejo industrial. Pero, no obstante las heterogéneas percepciones y vivencias, puede afirmarse que el ex dueño logró transmitir entusiasmo por el 'proyecto Elenic' a varios de los empleados que luego conformaron la cooperativa. Aunque algunos, como Ferraro, mantenían cierta distancia respecto de Takopian, otros trabajadores, como el Loco, dejaban el alma en la fábrica, porque tenían buenos sueldos, porque creían que podían crecer dentro de Elenic y porque sentían que si a Elenic le iba bien, también a ellos les iba bien. 


\section{II}

La descripción recién desarrollada nos permite reflexionar sobre varios asuntos. Evidentemente, existía un juego de identificaciones establecidas a partir de la relación complementar/oposicional que se generaba en el mismo vínculo laboral, entre el fundador - ex dueño y patrón-y los empleados de la empresa. La posición que cada uno ocupaba en la trama relacional ofrecía la base del sustento de las identificaciones del tipo dueño/trabajador, o patrón/empleado. Es fácil ver el aspecto activo, flexible, móvil y procesual de la identificación (Brubaker y Cooper 2001), pero también cuáles son los límites sociales concretos del abanico de identificaciones posibles en este contexto específico. Don Germán podía identificarse como laburante y sostener esa identificación en ciertos rasgos socialmente objetivados, tales como tener manos de trabajador, haber trabajado codo a codo con ellos, hablarles en su mismo lenguaje. Pero, evidentemente, un trabajador o laburante no podía identificarse como dueño o patrón en dicho contexto relacional. En este caso, al no poseer las características que le permitieran sostener socialmente esa identificación, no podía ocupar esa posición. Así, los del círculo íntimo de Don Germán, eran llamados patronales, calificativo que también se extendía a todos aquellos que tenían actitudes que mostraban afinidad con el dueño y/o con los jefes que organizaban la empresa. Por ejemplo, en algunas ocasiones escuché a otros miembros de la cooperativa nombrar al Cejas como patronal.

Al mismo tiempo puede observarse que, aunque las ubicaciones de los sujetos en el todo social señalan lindes, fronteras, límites, las identificaciones no totalizan a los sujetos que están ubicados en una cierta posición dentro de una relación laboral. Y esto es así no solo porque la adhesión a valores o situaciones aparentemente contradictorias entre sí es perfectamente posible (se puede mantener el respeto por Germán Takopian y liderar el proceso de recuperación de un fábrica, simultáneamente; tal fue la situación del Loco Flores), sino también porque, como vimos, personas ubicadas en una misma posición social, como operarios de línea de la Planta 1 de Elenic S.A., se relacionaron de modos diversos con el patrón. Así lo muestran las diferencias entre el Loco, el Cejas y Ferraro. $Y$ es el modo heterogéneo que adquirió en cada caso esa relación (personal, simbólica y moral), lo que explica, en parte, cómo se fueron diferenciando las trayectorias de estos tres trabajadores dentro de la empresa.

Vimos que en la fábrica había, por un lado, sujetos que ocupaban posiciones disímiles y, por otro, sujetos con ideas y sentimientos diferentes al interior de las mismas posiciones. Sin embargo, a pesar de estas heterogeneidades, creemos que la unidad fabril se constituyó como un espacio social donde los individuos han llegado a considerarse parte de un colectivo mayor. No eran iguales y tenían diversas percepciones y valoraciones, pero los ex trabajadores de Elenic que actualmente conforman la cooperativa sienten haber sido parte de una trama social, parte de una gran empresa nacional. Refieren haber formado parte de una comunidad, la importante comunidad de trabajadores de Elenic, compuesta por más de 7000 empleados distribuidos en varias plantas en todo el país. Algunos podían ignorar el sistema de premios y promociones de la empresa, otros aceptarlo. Podían sentir admiración, rabia y/o respeto por el viejo industrial. Pero, en tanto miembros de Elenic, crearon y experimentaron, al mismo tiempo, relaciones corporativas de pertenencia, diferencia e identificación mutua, cargadas de emotividad. 
Según Benedict Anderson, "todas las comunidades mayores que las aldeas primordiales de contacto directo (y quizá incluso estas) son imaginadas" (1993: 24). La definición se aplica al caso de la ex Elenic. El conjunto de directivos, empleados y obreros fueron miembros de una trama relacional donde se imaginó que el grupo constituía una comunidad de tipo familiar, en la cual el valor del 'progreso' ocupaba un lugar central. Esta imaginación, no fue homogéneamente compartida por todos, pero constituyó una de las ideas predominantes dentro de la fábrica mientras esta estuvo bajo patrón. En este aspecto, el concepto de "solidaridad jerárquica", apuntado por Sahlins (1988: 57-58) para referir a sociedades heroicas que no son ni orgánicas ni mecánicas (donde la coherencia no es dada ni por la similitud ni por la complementariedad), resulta útil para describir el modo en que se tejían las relaciones en esta especifica "comunidad imaginada".

\section{LA TRANSFORMACIÓN}

\section{I}

En el año 2000, Germán Takopian cedió la dirección de la empresa a su hijo menor, Fernando, y se retiró22. Decidió dar un paso al costado, apostando al recambio generacional. Hacia septiembre del año 2001, el nuevo directorio decidió cerrar la Planta 1 de Santa Catalina y llevar parte de sus máquinas al parque industrial de Las Sardinas. Allí se emplazaban la Planta 12, donde se producían suelas para el calzado, y la 41, que funcionaba como área de depósito y reparto de mercancías. La mitad de los trabajadores de la Planta 1 fue despedida. Al resto se le ofreció ir a trabajar a la Planta 12 de Las Sardinas, a un área específica que se organizó con las máquinas trasladadas desde la Planta 1, para realizar las mismas tareas de antes (costura de la parte superior del calzado, unión de esa parte con las suelas, finalización y empaque del calzado para la distribución a los comercios del ramo) en el nuevo lugar. Para muchos trabajadores que vivían en Santa Catalina la Planta 12 quedaba muy lejos, pero no había muchas alternativas. Si no aceptaban trabajar allá la única opción disponible era la de ser despedidos. Algunos prefirieron esta segunda opción, y organizaron con los encargados de personal el pago en cuotas de los salarios atrasados y de la indemnización por despido. Pero, al poco tiempo, la empresa, que venía arrastrando desde mediados de 1990 una deuda de varios millones de dólares, ingresó en un concurso preventivo de acreedores ${ }^{23}$. Entonces, los trabajadores despedidos se dieron cuenta de que no iban a poder cobrar.

Si bien no contamos con datos exactos, el testimonio de algunos ex asalariados de la empresa indica que en aquella época había cerca de 400 trabajadores en Santa Catalina y alrededor de 600 en Las Sardinas, y que entre ambas sedes se expulsaron cerca de 350 empleados. El resto se dividía ente trabajadores activos y suspendidos ${ }^{24}$. Los trabajadores de Santa Catalina fueron los más afectados con cerca de 200 despedidos.

Una fracción de los cesanteados de ambas sedes desarrolló una serie de acciones de protesta frente a la Planta 1 y realizó reclamaciones en ámbitos gubernamentales y judiciales. Buscaban, al mismo tiempo, recuperar el empleo, el reconocimiento de los pagos adeudados y ser indemnizados. Se abrió un largo y muy arduo proceso 
de lucha, que ocupó varios años y tuvo diversas etapas. Las energías se concentraron en Santa Catalina porque allí estaba el centro administrativo de Elenic, frente a la Planta 1, y porque era más fácil cortar calles en ese barrio que en el acceso al parque industrial de Las Sardinas, donde se podía ver afectada la circulación de trabajadores de otras empresas de la zona.

Al núcleo de despedidos que desarrolló las acciones de protesta se le dio el nombre de luchadores; ellos resistieron e hicieron el aguante más de un año en la calle ${ }^{25}$. Quemaron gomas, cortaron calles, llenaron de basura el acceso a la sede administrativa ${ }^{26} \mathrm{e}$ impidieron, en algunas ocasiones, que los directivos ingresaran a la empresa. Las acciones de protesta desarrolladas en los alrededores de la Planta ${ }^{27}$, que incluyeron el emplazamiento de una carpa en la entrada de la fábrica en el verano de 2003 y la organización de una maratón "Por la Dignidad del Trabajo" desde la plaza del Municipio de Santa Catalina hasta la puerta de la fábrica, contaron con el apoyo de familiares, vecinos del barrio, militantes de organizaciones sociales y políticas, estudiantes universitarios y militantes del Movimiento Nacional de Empresas Recuperadas. Hasta los choferes de colectivo de la zona apoyaban a los trabajadores de Elenic en lucha, permitiéndoles viajar gratis cuando subían a los medios de transporte que circulaban por allí. Hoy en día sobreviven algunas marcas de ese período en las paredes externas de los edificios. Por ejemplo, donde estaban ubicadas las oficinas centrales puede leerse, escrito con pintura en aerosol: "Por una Elenic Obrera". En la entrada principal de la fábrica, se lee: "El Grupo Elenic se desintegra por tanto engrupir ${ }^{28 " .}$ Otras frases, también escritas con aerosol, se van diluyendo con el tiempo: "Delegados traidores", "Delegados ladrones"29, "Tenemos hambre Elenic. Paganos".

Frente a los despidos masivos, se activó la alterización nosotros/ellos, aumentando el contraste de la relación patrón/empleado. En el contexto del conflicto provocado por la decisión de cerrar la fábrica y con Fernando, el hijo de Germán, conduciendo la empresa, la diferencia entre ambos grupos se convirtió en algo muy relevante, que acompañó el accionar de la protesta radical.

\section{II}

Ante la situación extrema, Don Germán Takopian no quiso quedarse de brazos cruzados. Hacia finales de 2002 volvió a la dirección con la idea de reactivar Elenic. Pero su nuevo período de gestión duró apenas un año, pues en octubre de 2003 fue desplazado por quienes integraban la mayoría del directorio de Elenic, conformado por buena parte de su entorno familiar. Durante ese año de gestión Don Germán lanzó una nueva marca de calzado y ropa deportiva, obtuvo un importante subsidio del gobierno nacional —bajo la presidencia de Eduardo Duhalde-, reabrió la "nave insignia" de Elenic, la Planta 1 de Santa Catalina, y re-contrató a trabajadores despedidos de esa sede y de Las Sardinas.

Nuevamente al mando, y contra la opinión de algunos miembros de su entorno, Takopian propuso a quienes realizaban acciones de protesta en la puerta de la Planta de Santa Catalina reincorporarlos poco a poco. Estos, organizados en una Comisión de Desocupados, aceptaron la propuesta. En febrero de 2003 firmó un acuerdo 
con los representantes de dicha comisión. En él se comprometía a incorporar a 120 trabajadores consignados en un listado; a cambio se les solicitaba que levantaran las carpas ubicadas en la puerta de la Planta y que evitaran "manifestaciones que alteren el orden público". Los luchadores, consideraron este hecho una victoria.

Se reactivó la producción. Sin embargo, las dificultades no tardaron en llegar: el gobierno nacional —ahora con Néstor Kirchner como presidente electo-se negó a otorgar un nuevo préstamo y se perdió definitivamente la licencia Brisas ${ }^{30}$. La situación económica de la empresa era débil. Los pagos salariales habían comenzado a demorarse otra vez y los trabajadores volvieron a verse suspendidos. Las partes volvían a enfrentarse. La iniciativa de Don Germán se desvanecía mientras las tensiones crecían. El lazo de interdependencia que había cortado el hijo y que el padre intentó restaurar volvió a verse hendido. De manera simultánea, se fueron profundizando las discrepancias entre Germán y Fernando Takopian. Sintiéndose traicionado por personas de su confianza y expulsado por su propio hijo, Germán volvió a separarse de la dirección de Elenic el 1 de octubre de 2003.

En ese momento los /uchadores tenían más recursos que a finales de 2001. No solo habían acumulado experiencia y contactos políticos, ahora habían pasado de la protesta callejera al interior de la fábrica, como empleados re-contratados. Tras el vacío en que quedó la empresa luego de que Don Germán fuera desplazado por sus allegados cercanos, decidieron ocupar la planta, a finales de octubre de 2003. Luego, comenzaron a desarrollar una serie de gestiones y reclamaciones en ámbitos judiciales y gubernamentales para lograr que se les otorgara la expropiación de la fábrica. En abril de 2004, a partir de la autorización del juez que intervenía en la denominada "causa Elenic", comenzaron a gestionar la fábrica de Santa Catalina bajo el formato legal de "cooperativa de trabajadores". En septiembre, se decretó la quiebra de la empresa. En diciembre del mismo año, la Cámara de Diputados de la Provincia de Buenos Aires, siguiendo los pasos del Senado, votó la expropiación de la unidad productiva (junto con sus inmuebles, maquinarias e instalaciones), que fue cedida en comodato a los trabajadores por cinco años. Gracias a esa medida se evitó que la fábrica fuera subastada (junto con otras plantas y activos de la firma), destino que le esperaba tras la declaración de quiebra de Elenic. Así nació la Cooperativa Crispín. Para los trabajadores se abría un nuevo proceso: antes habían estado bajo patrón, ahora todos eran dueños.

\section{TOMAR O NO TOMAR LA FÁBRICA}

Si alguien llega a la Cooperativa Crispín con intenciones de conocer cómo la importante $-\mathrm{y}$ famosa- empresa Elenic S.A. se convirtió en una "empresa recuperada" tiene muchas chances de escuchar relatos que, imbuidos de un vívido dramatismo, lo envolverán en una evocación heroica y triunfal. Pero se irá de la fábrica totalmente confundido. Pues tomar la fábrica no fue algo directo. Aquellos que se atrevieron, un grupo pequeño, fueron haciéndolo poco a poco. A continuación realizaremos una breve descripción de las diversas actitudes y los diferentes modos de experimentar una misma situación. La descripción nos permitirá dar cuenta del interrogante que planteamos en el inicio de este trabajo: ¿cómo se construye y materializa la idea de que tomar y autogestionar una fábrica es una alternativa para trabajadores que por años trabajaron bajo patrón? 
En octubre de 2003 la iniciativa de Eduardo Takopian había fracasado y con el retorno de su hijo Fernando las cosas empeoraron, pues se cerraron casi todas las plantas que Elenic tenía en el país, aumentando así el caudal de desocupados que generaba la empresa. Sin embargo, algunos empleados administrativos, e incluso de mantenimiento y jerárquicos, siguieron yendo a realizar sus tareas diarias en la Planta 1, pues nadie les avisó de que hicieran lo contrario. La empresa estaba a la deriva.

Los operarios que habían logrado ser recontratados por Elenic a inicios de 2003 se veían nuevamente sin trabajo. Se sumaban los otros, los que habían trabajado hasta ese momento en Las Sardinas (grupo constituido por los obreros de esa sede que no fueron despedidos en 2001 y por los ex miembros de Planta 1, que decidieron ir a trabajar lejos de sus casas aunque la paga fuera magra, porque peor era estar sin trabajo). Estos grupo se agolpaban en las puertas de las edificaciones de Santa Catalina, la sede central de Elenic, pero nadie podía darles una respuesta cierta. A pesar de ello, muchos cesanteados creían que las cosas podían mejorar, tenían la esperanza de volver a trabajar, pensaban que los podían volver a llamar. Ya había sucedido antes.

Los luchadores ya habían conformado una cooperativa de trabajadores y algunos creían que la única alternativa era tomar la empresa. Pero, a pesar de que los cesanteados eran muchos, pocos se atrevían a dar el paso. En medio de la incertidumbre y las dudas, el núcleo de los /uchadores, seguidos por algunos otros, decidió ocupar la planta. Se dice que eso sucedió un 17 de octubre de 2003.

La ocupación fue un acto decisivo, pero respetuoso y discreto. Consistió en ingresar al hall central de la fábrica. Luego ingresaron al sector de baños y vestuarios de los operarios y al pasillo que comunica este sector con el área productiva de la empresa. Pero nadie se atrevió a traspasar los límites de dicho pasillo. Nadie se atrevía a romper el candado que cerraba el paso hacia el sector de producción. Por varios días, los operarios vivieron allí, comieron allí, durmieron allí, pero no daban un paso más. Cuidaban de que los dueños de la empresa no se llevaran las máquinas pero no se atrevían a tomar algo que no era de ellos.

Aunque, desde fines de 2001, los trabajadores se habían informado de la existencia de empresas recuperadas; aunque habían armado una cooperativa; aunque habían conocido a obreros de otras empresas en crisis que, luego de tomarlas, generaron procesos de autogestión; aunque tenían el asesoramiento de activistas que los incentivan a "dar el paso"; romper el candado, pasar la línea, que separaba el pasillo del área de producción no era tarea sencilla. Pasó mucho tiempo, como un mes, hasta que se atrevieron a romper el candado. En cuanto lo hicieron comenzó el proceso de organizar la autogestión.

La decisión de tomar la fábrica y comenzar a producir dividió aguas entre los desocupados de Elenic. Muchos no quisieron acompañar la toma, ni tampoco la Cooperativa luego. Se burlaban de los que tomaron la fábrica diciendo que no la iban a poder mantener, que no sabían manejarla. Otros pensaban que la acción era algo fuera de lo legal, casi como robar. Esa era la opinión de "La Gringa" Chávez, una ex trabajadora de Elenic que fue incorporada a la cooperativa en al año 2006, en un momento donde había mucho trabajo y la Cooperativa contrató nuevo personal especializado, privilegiando a ex empleados de la empresa. Ella no se sumó antes a la cooperativa porque no consideraba que esa fuera una buena idea. Lo hizo recién cuando Crispín estaba plenamente establecida, 
con necesidad de mano de obra calificada, y ella, una mujer que hacía tiempo había pasado los cuarenta años de edad, no podía conseguir un empleo formal, estable y bien pago en otro lugar ${ }^{31}$.

Otros ex trabajadores de Elenic, se sumaron de manera contradictoria y tímida en los inicios del proceso, hasta que adquirieron más confianza. Veamos, por ejemplo, el caso de María, una de las primeras en sumarse a la Cooperativa Crispín poco tiempo después de la toma ${ }^{32}$ :

Carina: ¿Vos, te uniste a la cooperativa cuando se quedaron sin trabajo allá en Las Sardinas?

María: Allá, dos veces nos suspendieron. Y en la última suspensión que tuvimos después no nos llamaron más. Y ahí empezó todo lo que se vino después. Que decían que parecía que ya quebraban. Estábamos a la expectativa de lo que iba a pasar. Nosotros ya no cobrábamos más nada.

Carina: Y ahí, ¿qué hiciste?

María: Y bueno, acá se empezaron a quedar [se refiere a la ocupación de la zona de vestuarios]. Y yo empecé a venir y mi hija también. Pero ella no fue a las marchas, yo sí. Comíamos los guisos que hacía Don Sánchez, después íbamos a las marchas. Y así fue hasta el día que tomaron la decisión de entrar.

Carina: Ese fue un día clave, el día en que toman la decisión de entrar al área productiva de la fábrica, ¿no?

María: Bueno, ahí yo no estuve cuando entraron ellos [se refiere a los que tomaron la fábrica]. Ese día no vine. Así que no sé como fue el día en que entraron. Yo los acompañaba para todos lados, a las marchas... La gente de Elenic no quería venir a trabajar a la Cooperativa Crispín porque estaban esperando que los llamaran de vuelta los Takopian. Pero yo igual los acompañaba. Fuimos al centro, al juez, fuimos a La Plata. Por todos lados íbamos nosotros, y yo andaba con ellos. Pero después, ya me dio cosa cuando entraron. Yo estaba con la desconfianza. La desconfianza. Pensaba lo mismo que pensaban los demás, que por ahí nos volvían a llamar de Elenic. Y si vos estabas en la cooperativa, ¿quién te iba a llamar? Todos tenían la esperanza de volver a trabajar [en Elenic]. Pero ya una vez que entraron ellos [los que tomaron la fábrica] acá..., bueno. No sé si hacía 20 días que habían entrado acá y vine.

Carina: Te atreviste.

María: Mi hija había conseguido un trabajo y yo, que estaba sin trabajo, la atendía a su hija, mi nieta. Yo la llevaba al jardín, la traía. Y ellos ya habían entrado acá, a la fábrica, con la cooperativa, a trabajar. Y yo digo: "seguro que estos cuando me vean me van a decir 'y vos ¿cuándo vas a venir a trabajar?'". Yo soy de la Iglesia Evangélica. Entonces yo agarré y antes de salir ya me tomé la precaución. Porque uno no sabe si está bien lo que hace, o no. Entonces yo le pedí la dirección a Dios. Le dije: "Señor, lo dejo todo en tus manos, que sea tu voluntad, si realmente es conveniente, o no, que yo vaya a trabajar a la cooperativa, que sea tu voluntad". Cuando entré acá, el Loco Flores, me mira y dice: “¿y vos cuándo vas a venir a trabajar?". Y yo poniéndole excusas, ipor que eran excusas! Le dije: "mirá, mi hija está trabajando y yo estoy atendiendo a la nena, la llevo al jardín, la traigo". Era una excusa para salvarme. "Así que yo estoy cuidando a mi nietita", le dije. "Tráela", me dijo. “Tráela a la nena, isi vamos a abrir la guardería! Dale. Tráela, vamos a reabrir el jardín. La dejás en el jardín y venís a trabajar". Ahí yo ya no tenía excusas... Así que ahí nomás me compró. Y yo tomé la decisión, iporque era tan clarito que sí! Realmente tenía que venir. Y me vine. Una vez que se limpió el jardín traje a la nena. Yo venía a trabajar y la traía a ella ahí. A mi nietita. Para mí fue una bendición, porque había mucha gente que estaba muy triste, pasándola mal realmente, esperando que la llamaran para volver a trabajar en Elenic y no la llamaban. En cambio nosotros, era una cosa linda. Estábamos trabajando. Era como una cosa reconfortante para nosotros. Trabajar, estar en tu lugar de trabajo. De a poquito, nos fuimos levantando.

Cada año, cuando llega el 17 de octubre, se festeja un nuevo cumpleaños de la Cooperativa Crispín. Efectivamente, ese día, en 2003, se inició la recuperación de la empresa por parte de sus trabajadores. En dicho contexto la distinción entre los conceptos ocupar y tomar (que a su vez son sinónimos según el diccionario de la Real Academia Española), no parece ser muy relevante. Sin embargo, algunos intérpretes nativos, como Ferraro, consideran importante establecer una diferencia. Con rigurosa precisión histórica y analítica Ferraro señala una 
clara distinción entre un momento y otro: primero se metieron en la fábrica (la ocuparon), luego se apropiaron de ella (la tomaron). Entre un momento y otro pasó bastante tiempo y los que se atrevieron a tomar la fábrica no superan un puñado de diez o doce personas. Entre ellos se encontraban el mismo Ferraro y El Loco Flores. Era un grupo pequeño, que había tomado confianza y generado amistad durante el período de lucha iniciado a finales de 2001, que se encolumnaba tras la guía carismática del Loco Flores, líder indiscutido de los luchadores durante todo ese tiempo y, posteriormente, Presidente de la Cooperativa Crispín.

Sin embargo, a diferencia de Ferraro, el Loco Flores postula que el 17 octubre se tomó la fábrica; no importa si primero fue apenas un pedacito: se tomó y listo. Esa postura también tiene que ver con cierto pragmatismo político; para el Loco no es necesario andar dando vueltas con minucias. Pero, más allá del modo en que sean enunciadas, las distinciones entre una y otra acción han señalado clivajes entre las personas involucradas, como muestran los testimonios de la Gringa Chávez y María, las dos mujeres arriba citadas. La primera se sumó a la cooperativa más de dos años después, cuando indiscutiblemente la empresa ya no estaba en manos de los Takopian. La segunda lo hizo poco tiempo después de la toma, como muchos otros que ese día no estuvieron, pero que apoyaron y se sumaron al proceso iniciado por quienes se atrevieron a dar ese paso fundamental.

\section{BREVE PUNTEO DE LAS HETEROGENEIDADES EN LA COOPERATIVA}

Luego de la toma, el grupo de los luchadores quedó a cargo del cuidado de la fábrica. Cuando obtuvieron la autorización judicial para poder producir, reactivaron las máquinas y reorganizaron la producción. También se contactaron con clientes, proveedores, bancos y asesores externos. Dentro del grupo, el núcleo más activo de luchadores conformó el primer Consejo de Administración de la Cooperativa, con el Loco Flores como Presidente. Quienes tomaron la fábrica convocaron e incorporaron a todo aquel que quisiera sumarse, pues cuanto mayor fuera el número de asociados a la Cooperativa mejor utilizada sería la capacidad productiva de la empresa y se haría más sostenible el proyecto de autogestión.

Así, el proceso histórico abierto tras los despidos masivos de 2001 produjo el surgimiento de nuevas categorías. Por un lado, se incorporaron trabajadores nuevos, personas que nunca habían trabajado en Elenic S.A. Son familiares, vecinos y conocidos de los viejos, a quienes se capacitó en los diferentes oficios que requería la fábrica. Por otro lado, se encuentran los trabajadores viejos de Elenic, que provienen de la Planta 1 de Santa Catalina y de las Planta 12 y 41 de Las Sardinas. Los trabajadores viejos, a su vez, se distinguen ente sí.

Desde los primeros despidos hasta la toma de la fábrica a fines de 2003 hubo un núcleo de personas muy activo en el proceso de reclamación, protesta y negociación: los luchadores. Luego se encontraba el grueso de los cesanteados (echados o suspendidos) que seguían el desarrollo de las protestas y negociaciones de diferente modo. Por un lado, están aquellos que se sumaban a ciertas acciones específicas y mantenían contacto con los más activos en altos niveles de compromiso, intervención y comunicación. En algunos casos, el apoyo a la protesta 
se organizaba a nivel familiar: por ejemplo, si un trabajador no podía estar presente en una acción (porque había encontrado algún trabajito por ahí) mandaba a su esposa. Algunos iban durante el día, pero no se quedaban por la noche. Otros enviaban comida a los que estaban haciendo el aguante. Y así. Por otro lado, se encuentra un grupo que no participó del proceso de lucha y que se unió al proyecto de la cooperativa luego, en diferentes etapas y momentos. Entre ellos se encuentran los que se unieron tempranamente a la Cooperativa, entre 2003 y 2004 , y los que se sumaron varios años después, a inicios de 2006.

Muchos ex trabajadores de Elenic que no estuvieron en la toma por diferentes motivos (porque no se atrevían, porque justo ese día no estaban, etc.), como María, y muchos que no estuvieron durante el proceso de lucha y aguante, como el Cejas, se sumaron pronto a la cooperativa, entre fines de 2003 e inicios de 2004. Otro grupo, compuesto por la Gringa Chávez y varios más, se sumó a la cooperativa mucho tiempo después, cuando esta ya estaba organizada. La distinción de las personas según si estuvieron o no en la lucha, o si estuvieron o no en la Cooperativa desde los inicios, también señala fronteras y límites. En la actualidad, genera tensiones e interviene en las relaciones de poder dentro de la empresa recuperada.

\section{A MODO DE CIERRE: 'CULTURA FABRIL' Y EXPERIENCIA(S)}

En este trabajo buscamos comprender a los ex trabajadores de la ex Elenic a partir del acercamiento a su(s) experiencia(s) y a los elementos morales y simbólicos que constituyeron la cultura (Sahlins, 1988) de aquellos que gestionan esta empresa. En particular, nos interesamos en conocer cómo se organizó una específica 'cultura fabril' durante los años en que los jefes y el patrón eran responsables de organizar la producción y cómo ella se desenvolvió en el proceso de ocupación, toma e inicio de la nueva situación de autogestión.

Afirmamos que es posible analizar el modo en que se constituye, despliega y transforma el conjunto de configuraciones simbólicas y morales de los sujetos que forman este colectivo como 'cultura fabril'33; si se parte de una consideración que comprende que la cultura no sofoca lo idiosincrático, y que los individuos nunca pueden ser reducidos a ella, aunque en parte los constituya. Las diferentes opiniones que los trabajadores tenían de las acciones de Germán Takopian son un ejemplo del complejo modo en que se entrelazaban las individualidades con las configuraciones de más largo alcance.

Llamamos 'cultura fabril', de los trabajadores de Crispín/ex Elenic, al conjunto de configuraciones simbólicas y morales de los que transitaron y transitan en la empresa de manera cotidiana. Consideramos que dicha 'cultura fabril', aunque es elástica, no homogénea, flexible y porosa respecto del mundo externo, posee rasgos propios, fruto de la interacción 'situada' de los sujetos en su contexto histórico. A su vez, es fruto de la actividad creativa de esos sujetos, que la reproducen y la alteran: la experiencia constituye la cultura y la cultura constituye la experiencia. En este sentido, la perspectiva que proponemos considera que 'la novedad' (ser despedidos repentinamente, protagonizar acciones de protesta y reclamación, ocupar y tomar la fábrica, etc.) es leída por las estructuras 
simbólicas de los sujetos pero, a su vez, plantea que estas estructuras son objetos históricos, contingentes, que pueden cambiar ante la novedad.

A su vez, la experiencia etnográfica muestra cómo, en la dinámica que plantea 'la novedad', intervienen los diversos posicionamientos e idiosincrasias individuales de un modo muy ágil. Para analizar esta dinámica particular recurrimos al concepto de experiencia(s). Es una referencia al clásico trabajo de Thompson "La Formación de la clase obrera en Inglaterra" (1989), pero enfatizando la(s) experiencia(s) en plural, sin por ello olvidar aquello que pueden tener en común, aquello que les puede dar una unidad.

En este texto, describimos cómo era la dinámica social en las épocas en que la fábrica estaba bajo patrón —uno de tipo paternalista-, cuando la idea de que Elenic era una comunidad de tipo familiar donde se podía 'progresar' ocupaba un lugar central. Esta cultura, que se crea en un contexto de relaciones diferenciadas patrónempleado configura, a su vez, un espacio donde el paternalismo como experiencia plural, como práctica y como expresión simbólica, generaba un aglutinamiento tal que articulaba aspectos contradictorios, ya que a la vez que había una diferenciación jerárquica y económica, los individuos podían sentir, y experimentar, que pertenecían a una comunidad mayor: la Comunidad Elenic.

De manera paralela, describimos diferentes modos de articular la pertenencia dentro de la comunidad de trabajadores de Elenic: cómo se entablaban relaciones de alteridad (de modo complementar y oposicional) y cómo las diversas identificaciones intervenían en las relaciones de poder a lo largo del proceso. También describimos el modo en el que se articulaban las relaciones entre las personas que circulaban en la fábrica durante el proceso de crisis y su resolución, pasando por los despidos masivos, la lucha, el intento fallido de volver instaurar la fábrica bajo patrón y, finalmente, la ocupación y toma de la unidad productiva.

Por último, mostramos cómo la toma resultó ser un hecho conflictivo para los ex trabajadores de Elenic y que (independientemente de que muchos se hayan sumado luego) solo un grupo muy pequeño se atrevió a dar el paso de 'apropiarse' de la empresa por completo.

La descripción puso la mirada en la heterogeneidad y diferencia que existe entre los sujetos. Buscamos ver la transformación de un colectivo a partir de la descripción de los diferentes modos de experimentar las situaciones que les tocó vivir a sus integrantes, sin forzar, a priori, una supuesta unidad u homogeneidad identitaria. Más bien, nuestro texto es apenas un intento de análisis del complejo entrelazamiento entre la dimensión colectiva y la individual (en sus niveles experiencial y simbólico). Tanto en el análisis de las relaciones patrón/empleado como en la descripción del proceso de ocupación y toma de la fábrica intentamos comprender cómo se despliegan las idiosincrasias y las experiencia(s) en plural sin, por ello, desechar la posibilidad de pensar en "lo cultural" y "lo social". La orientación la brindó el mismo trabajo de campo, que nos abrió la posibilidad de hacer el estudio etnográfico de una 'cultura fabril' sin dejar de desarrollar, de manera simultánea, una etnografía de sujetos particulares insertos en estructuras mayores en cuyo contexto se expresan.

Carina Balladares é doutoranda e professora na Facultad de Ciencias Sociales da Universidade de Buenos Aires 


\section{NOTAS}

1 Este texto es una versión modificada y ampliada del presentado en la $27^{a}$ Reunião Brasileira de Antropologia (agosto de 2010, Belém do Pará, Brasil), en el GT "Antropologia do Trabalho".

2 En este artículo uso la letra cursiva para resaltar categorías con cierto peso en la simbología de los agentes del procesos bajo estudio; cursiva y comillas dobles para sus frases textuales; comillas dobles sin cursiva para resaltar categorías de origen externo -eruditas, militantes, etc. - a los actores del proceso que estudiamos; finalmente, las comillas simples se usan para resaltar categorías de 'nuestra' descripción.

3 Cfr. OSERA (2009) y Programa Facultad Abierta FFyL-UBA (2010).

4 Entre los estudios que se dedicaron a seguir este fenómeno una de las inclinaciones predominantes se relaciona con la irrupción del fenómeno como 'novedad' en el contexto de otras 'novedades', como movimiento en el contexto de otros. Así, se analizaron las recuperaciones como acciones colectivas, rastreando antecedentes históricos y continuidades de prácticas tales como la toma de fábricas (Fernández Álvarez 2006; García Allegrone et al. 2004), o poniendo el acento en la constitución de un nuevo repertorio enmarcado en el ciclo de protestas más amplio de inicios de nuevo siglo (Fajn 2003; Dávolos \& Perelman 2003; Gracia \& Cavaliere 2007). A su vez, se investigó tanto el activismo político como la emergencia de diversas organizaciones que promueven el surgimiento y desarrollo de las empresas recuperadas (Rebón 2006; Gracia \& Cavaliere 2007; Gracia 2008). Se analizó tanto el contexto de oportunidades económicas, sociales y políticas del fenómeno como el papel del estado en el desarrollo de este tipo de procesos (Fajn 2003; Fernández Álvarez 2006; Gracia \& Cavaliere 2007). Algunos analistas se dedicaron a indagar el papel jugado por ciertos sindicatos y trabajadores con experiencia sindical en el desarrollo de los movimientos de recuperación de empresas (Dávolos \& Perelman 2003, 2004; Aiziczon 2007). Se indagó sobre las ventajas que podría tener el fenómeno en términos de la experimentación de nuevos estilos organizacionales y como nuevas experiencias de economías solidarias, sociales, alternativas (Ghibaudi 2004; Wyczykier 2007; Vieta 2009). También se analizaron los procesos, estrategias y contextos legales, que pueden facilitar, o no, la gestión de las unidades productivas por parte de sus trabajadores (Fajn 2003; Echaide 2004; Gracia \& Cavaliere 2007; Gracia 2008).

5 Se ha postulado la idea de que habría "rupturas" y "cambios" en las subjetividades (Fajn 2003; Cafardo \& Domínguez Font 2003) a partir de estas nuevas vivencias. Se ha operacionalizado el concepto de "conciencia de clase" para describir percepciones y actitudes de los trabajadores en cuestión (Rebón 2004, 2006). Se ha indagado en los sentidos asociados al trabajo y las características identitarias de los protagonistas de estos eventos (Bialakowsky et al. 2003; Fernández Álvarez 2004, 2006; Fernández 2006).

6 En el trabajo de campo realizado para la tesis (en proceso de redacción final), las herramientas clave fueron la observación participante y las entrevistas no dirigidas y semiestructuradas, a las que se sumaron el análisis de material de archivo y diversas fuentes secundarias. Con los insumos obtenidos, desarrollamos un estudio etnográfico de las diversas experiencias históricas de los trabajadores que autogestionan la empresa recuperada; las transformaciones de sus relaciones sociales; y la construcción, actualización y transformación de su 'cultura fabril'.

7 En este trabajo recurro al uso de pseudónimos para nombrar a las personas, a la empresa de referencia y al barrio donde se emplazaba la fábrica mencionada.

8 Santa Catalina es un partido del conurbano bonaerense que, durante buena parte del siglo XX, constituyó una pujante zona industrial del país. Hacia finales del siglo XX, sufrió un fuerte proceso de desindustrialización. Esto produjo la desestabilización de la vieja población asalariada y un importante aumento de los niveles de desocupación, vulnerabilidad, riesgo y desigualdad social. Aunque en este aspecto se parece a otras zonas del conurbano, en este municipio las respuestas sociales a la crisis tienen rasgos específicos, pues la recuperación de empresas se convirtió en una de las más destacadas respuestas a los efectos negativos de la globalización neoliberal. En Santa Catalina hubo diez empresas que emprendieron procesos de recuperación, de los cuales nueve se hicieron efectivos. No poseemos información sobre la cantidad exacta de recuperadas existentes en el país. Hace unos años se hablaba de un número aproximado de entre 180 y 200 casos de recuperación y más de 12.000 trabajadores involucrados, incluyendo éxitos y fracasos. Hacia el año 2008 el número ascendía a 219 casos conocidos (Osera 2009). Hacia fines del año 2010, y considerando los emprendimientos que se encuentran en funcionamiento, se habla de la existencia de 205 empresas recuperadas en el país; el área con mayor concentración de casos sería el Gran Buenos Aires donde hay 76 casos, un 37,1\% respecto del total nacional (Programa Facultad Abierta FFyL-UBA 2010). Tomando estas cifras como referencia, se puede decir que en Santa Catalina, donde hubo diez empresas que emprendieron 
procesos de recuperación, de los cuales nueve fueron efectivos, habría casi un 12\% del total de las empresas recuperadas del Gran Buenos Aires, lo que supone cerca de un $5 \%$ del total de casos de recuperación de empresas del país.

9 Por una cuestión de falta de espacio no detallaremos las diferencias entre las unidades productivas de Santa Catalina y Las Sardinas.

10 El fundador y ex dueño de Elenic escribió dos libros contando su historia y la de la empresa. El primer libro, publicado en el año 2000 , fue best seller. En ese momento la empresa ya estaba atravesando una fuerte crisis y su creador decidió retirarse, "dar un paso al costado", de manera voluntaria, para posibilitar la renovación generacional de Elenic. El segundo libro se publicó en 2004 , cuando la empresa se alejaba, cada vez más, de las manos de la familia fundadora. Hemos incorporado esos libros como parte del material de archivo de nuestra investigación mayor.

11 Se refieren a la crisis económica desatada en México en diciembre de 1994, la cual tuvo efectos recesivos en la economía argentina.

12 En ese momento, Germán Takopian, que nació en enero de 1930, contaba con 23 años de edad y un lustro de experiencia en la industria textil, trabajando junto a su padre. Actualmente tiene 80 años.

13 Tanto en el discurso del fundador de la empresa como en las narrativas de los trabajadores se resalta como hecho positivo que la empresa fue fundada y dirigida por un empresario nacional y con capital nacional. En términos del imaginario social, la positividad de la empresa nacional trasciende a los actores mencionados; tiene relevancia simbólica en vastos sectores sociales de la población argentina, incluso después de las transformaciones neoliberales de la década de 1990. Este imaginario está constituido por un arquetipo de nación vinculado al modelo de estado de bienestar -inclusivo y distributivo-y de una sociedad de pleno empleo, donde la industria nacional juega un papel central como motor del desarrollo del país. La experiencia del proceso de sustitución de importaciones desarrollado en Argentina durante el siglo XX, donde creció una industria local y se desarrolló una burguesía nacional, le da sustancia a este arquetipo. De modo muy general, se puede decir que, para este imaginario, esa burguesía nacional industrialista (diferenciada de otras burguesías - locales o extranjeras - que solo buscarían el beneficio del propio capital o, en todo caso, de la propia fracción de clase) tendría un mayor interés en el desarrollo del país y de los ciudadanos argentinos en general.

14 Testimonio tomado del primer libro publicado por el ex fundador de Elenic.

15 En el caso de los equipos de fútbol que organizaban los obreros de la planta, se disputaban campeonatos entre miembros de diferentes secciones de la fábrica, o entre obreros de Elenic y de otras empresas, siempre en un nivel amateur. Por su parte, el Equipo de las Estrellas no llegó a ser un "Club de Fábrica" propiamente dicho (Antunes 1994), que disputara campeonatos en la primera división, como fue el caso del equipo de fútbol de la empresa argentina Loma Negra, entre 1981 y 1983, o como fue el caso de varias empresas de Brasil. Al respecto, y para ver el papel del mundo industrial en la creación de la figura del operario-jugador en Brasil, pueden consultarse Leite Lopes y Maresca (1992), Antunes (1994) y Cioccari (2011), entre otros. En Argentina ese tipo de investigación aún no ha sido realizada.

16 También lo definían así algunos de los trabajadores a quienes entrevisté tras la recuperación de la empresa.

17 Ignacio recuerda el gesto con agradecimiento, y no deja de repetir, a todos los que pasamos por la portería de la empresa de manera cotidiana, que "el que era el dueño de esta planta que quebró, el señor Germán Takopian, ese para mí era un padre".

18 Así, se observa en esta empresa la configuración de un espacio simbólico donde el "paternalismo" (Sierra Álvarez 1990; Winn 1986; Barbero \& Ceva 1999; Farnsworth-Alvear 2000; Neiburg 1988, 1990; Leite Lopes 1976, 1988) como experiencia plural, como práctica, como organización moral y como forma de dominación, generaba un cierto tipo de afectividad y cohesión perdurables en el tiempo.

19 El Loco Flores ingresó a la empresa en 1985, con 21 años de edad.

20 Los trabajadores desgranan diversas críticas. Se refieren a la contratación de amigos de sus hijos para puestos jerárquicos (aunque no estaban lo suficientemente capacitados), y al pago de sueldos excesivamente altos a estos allegados. También aluden a la impunidad con la que se manejaban los delegados sindicales dentro de la empresa, y a numerosas arbitrariedades cometidas por personas cercanas a Takopian (autoritarismo, abuso de poder, etc.). Algunos consideran que estas situaciones eran responsabilidad última del dueño (el error de Don Takopian consistió en haberse rodeado de esa gente); otros piensan que eran provocadas por su entorno y no se puede culpar al empresario por las acciones de estos, pues él era otra cosa.

21 El Cejas ingresó a la empresa cuando tenía 20 años, en 1986. Trabajó allí hasta ser despedido en el año 2001, y luego en el período 2002-2003 en que fue recontratado. En su primera etapa recorrió diversos puestos dentro de las diferentes áreas de producción. En su 
segunda etapa, trabajó en el área de diseño y desarrollo de calzado, como asistente. De manera simultánea, durante el período 20022003, fue realizando los cursos de diseño y modelaje de calzado que pagaba Takopian. No pudo terminar el curso final, pues cuando la empresa cayó le resultó dificultoso sostener el costo del curso.

22 En ese momento, su hijo menor contaba con cerca de 40 años.

23 Según fuentes periodísticas, en 2001 la deuda de Elenic S.A. superaba los 350 millones de dólares. Esa cifra sufrió variaciones a lo largo del proceso judicial que se extendió hasta finales del año 2004.

24 Las cifras de referencia, que distinguían a los trabajadores despedidos de los suspendidos y de los activos, fueron variando desde los despidos masivos de septiembre de 2001 hasta el momento de la quiebra y cierre definitivo de Elenic, a fines de 2004.

25 Se llamó luchadores al colectivo de trabajadores más activo en el desarrollo y sostenimiento de las acciones de reclamación y protesta. Este grupo estaba constituido por unas 20 personas aproximadamente; su núcleo estaba compuesto por los más luchadores entre los luchadores, el cual posteriormente conformó la primera comisión directiva de la cooperativa, con Ferraro y El Loco Flores entre sus miembros más destacados. Luego había diversos grupos de trabajadores que se sumaban a ciertas acciones específicas y mantenían contacto con los más activos en diferentes niveles de compromiso, intervención y comunicación. Todos los ex empleados de Elenic seguían el desarrollo de las protestas y negociaciones. Unos cuantos (entre 120 y 180 ex trabajadores) se unieron al proyecto de la cooperativa, pero otra gran cantidad no. Para estos últimos esa no era una opción interesante o viable. Algunos (sobre todo los más calificados) consiguieron trabajo en empresas del rubro. Otros prefirieron armar un emprendimiento propio. Otros decidieron quedarse en sus casas, esperando la edad de la jubilación o a recibir la indemnización, cuyo cobro habían comenzado a tramitar por medios legales.

26 La administración de la empresa todavía funcionaba con unos pocos empleados.

27 Las acciones desarrolladas en la Planta 1 de Santa Catalina se convirtieron en 'ejemplo' a seguir por trabajadores de otras plantas pertenecientes a la 'comunidad Elenic'. Si bien en este trabajo nos centramos en la Cooperativa Crispín, resulta importante señalar que hay otras tres fábricas Elenic recuperadas en el país (la segunda se encuentra ubicada en el interior de la Provincia de Buenos Aires, la tercera en Corrientes y la cuarta, en La Rioja). El resto de las unidades productivas (incluidas las Plantas de Las Sardinas) fueron vendidas en el remate judicial.

28 Engrupir: hacer creer una mentira.

29 Es importante decir que, de acuerdo con los relatos de los trabajadores, durante los años previos a la crisis de la empresa (e incluso cuando esta ya se había declarado) los delegados sindicales y los sindicatos eran percibidos como más cercanos a los dueños de la empresa que a los trabajadores. Hay que destacar que los delegados sindicales de Elenic no acompañaron las acciones de protesta posteriores al cierre de la fábrica en 2001. Entonces, sintiéndose abandonados, un grupo de trabajadores despedidos quedó al frente de la movilización colectiva, se auto-organizaron como Comisión de Desocupados y terminaron por negociar de forma directa con la familia Takopian.

30 El contrato de Elenic para fabricar la marca Brisas había vencido a fines de 2001. Pero los directivos de Elenic confiaban en que, luego de 30 años de relación comercial, iba a ser posible llegar a un acuerdo para renovar el contrato de representación. Finalmente eso no sucedió.

31 La Gringa Chávez tiene 51 años de edad en al actualidad; ingresó a Elenic en 1985, con 27 años. A continuación, un fragmento de una entrevista:

La Gringa: Como te dije antes, yo creo que la honestidad de la gente hizo que pensaran que era algo malo [se refiere a tomar la empresa], venir a apropiarse de algo...

Carina: ¿Y cómo ingresaste acá? ¿Estabas en contacto con la cooperativa, te llamaron?

La Gringa: Porque una compañera entró y les habló de mí a los del Consejo de Administración y dijeron "sí, sí, que venga" y vine.

Carina: Igual vos sabías que había una cooperativa, que producían... ¿te enteraste de que les habían dado la expropiación, es decir que les habían dado la fábrica?

La Gringa: Es como que ya venía con algo formado, ya no sentías eso de que te estabas apropiando de algo que no era tuyo. Ya era algo, digamos, más completo, algo que no estaba tan mal, veníamos a un medio de vida. A seguir, digamos.. 
32 María tiene 61 años de edad e ingresó a Elenic en 1990, con 43 años.

33 En las últimas décadas, se sucedieron una serie de discusiones en torno a la definición y el uso del concepto cultura en Antropología. Algunas perspectivas han criticado determinadas aplicaciones del concepto, que han tendido a construir, desde una mirada profesional, un "otro" limitado por fronteras discretas, homogeneizando comunidades y ubicándolas en una cierta atemporalidad; esencializando y sobre-enfatizando la coherencia de las mismas (Appadurai 1988, 2001; Clifford 1988; Abu-Lughod 1991, 2005). Otras perspectivas han señalado la poca consideración de ciertos temas en algunas definiciones o utilizaciones: el poder, la agencia, la práctica, la historicidad y la subjetividad, entre otros (Ortner 1984, 2005). Mientras algunos proponen que debido a estos problemas sería conveniente abandonar el concepto cultura e incluso escribir "contra" él (Abu-Lughod, op.cit.) otros plantean reformarlo (Brumann et al. 1999; Ortner op. cit.). Porque tenemos en cuenta las objeciones mencionadas pero consideramos, a su vez, que el concepto cultura es una herramienta que posee utilidad explicativa en los análisis sociales, formulamos nuestra noción de 'cultura fabril'. En ella retomamos de manera central los aportes elaborados por Sahlins (1988, 1997a, 1997b) en la definición y aplicación del concepto. 


\section{REFERÊNCIAS BIBLIOGRÁFICAS}

ABU-LUGHOD, Lila. 1991. "Writing Against Culture". In R. G. Fox (org.) Recapturing Anthropology. Santa Fe: School of American Research Press.

2005. “La interpretación de las culturas después de la televisión”. Etnografías contemporáneas 1: 57-91.

AIZICZON, Fernando. 2007. "El clasismo revisitado. La impronta del trotskismo en la politización del sindicato ceramista: Zanón Bajo Control Obrero, Neuquén 1998-2006". Disponível em: http://www.iisg.nl/labouragain/ documents/aiziczon.pdf. Acessado em: 20/03/2009.

ANDERSON, Benedict. 1993. Comunidades imaginadas. México: FCE.

ANTUNES, Fátima Martin. 1994. “O futebol nas fábricas”. Revista USP - Dossiê Futebol 22.

APPADURAI, Arjun. 1988. "Putting Hierarchy in Its Place”. Cultural Anthropology 3(1): 36-49.

Trilce-FCE.

2001 [1996]. La modernidad desbordada. Dimensiones culturales de la globalización. México: Ediciones

BARBERO, María Inés \& CEVA, Mariela. 1999. "La vida obrera en una empresa paternalista". In F. Devoto \& M. Madero (orgs.) Historia de la vida privada en la Argentina, Tomo III. Buenos Aires: Taurus.

BIALAKOWSKY, Alberto et al. 2003. "Identidad y cultura en las nuevas formas de gestión y autogestión de los trabajadores". VI Congreso Nacional de Estudios del trabajo, los trabajadores y el trabajo en la crisis. Buenos Aires: ASET.

BRUBAKER, Rogers \& COOPER, Frederick. 2001. “Más allá de identidad”. Apuntes de investigación 7: 30-67.

BRUMANN, Christoph et al. 1999. "Writing for Culture: Why a Successful Concept Should Not Be Discarded", "Comments" and "Reply". Current Anthropology 40(1): 1-41.

CAFARDO, Analía \& DOMINGUEZ FONT, Paula. 2003. “Autogestión obrera en el siglo XXI. Cambios en la subjetividad de los trabajadores de empresas recuperadas, el camino hacia una nueva sociedad". Cuaderno de Trabajo 27.

CIOCCARI, Marta Regina. 2011. "Mina de jogadores: o futebol operário e a construção da "pequena honra"'. Cadernos Arquivo Edgard Leuenroth 16: 76-115.

CLIFFORD, James. 1988. The Predicament of Culture. Cambridge: Mass.

DÁVOLOS, Patricia \& PERELMAN, Laura. 2003. “Empresas Recuperadas y Trayectoria Sindical: La experiencia de la UOM Quilmes". In G. Fajn (Comp.) Fábricas y Empresas Recuperadas. Protesta social, Autogestión y rupturas en la Subjetividad. Buenos Aires: Ediciones del Instituto Movilizador de Fondos Cooperativos.

2004. "Acción colectiva y representaciones sociales: los trabajadores de empresas recuperadas". Disponível em: http://www.iisg.nl/labouragain/documents/davolos_perelman.pdf. Acessado em: 10/04/05.

DIAS DUARTE, Luis Fernando. 1986. Da vida nervosa nas classes trabalhadoras urbanas. Rio de Janeiro: Jorge Zahar Editor/CNPq. 
ECHAIDE, Javier. 2004. “Debate sobre Empresas Recuperadas. Un aporte desde lo legal, lo jurídico y lo político” Cuaderno de Trabajo 25.

FAJN, Gabriel (Comp.). 2003. Fábricas y Empresas Recuperadas. Protesta social, Autogestión y rupturas en la Subjetividad. Buenos Aires: Ediciones del Instituto Movilizador de Fondos Cooperativos.

FARNSWORTH-ALVEAR, Ann. 2000. Dulcinea in the factory: Myths, Morals, Men and Women in Colombia's Industrial Experiment, 1905-1960. Durham and London: Duke University Press.

FERNÁNDEZ ÁLVAREZ, María Inés. 2004. "Sentidos asociados al trabajo y procesos de construcción identitaria en torno a las ocupaciones y recuperaciones de fábricas de la Ciudad de Buenos Aires: un análisis a partir de un caso en particular". In O. Battistini (Comp.) El trabajo frente al espejo: Continuidades y rupturas en los procesos de construcción identitaria de los trabajadores. Buenos Aires: Prometeo.

2006. De la supervivencia a la dignidad. Una etnografía de los procesos de "recuperación" de fábricas en la ciudad de Buenos Aires. Tesis de Doctorado. UBA/L'École de Hautes Etudes en Sciences Sociales.

FERNÁNDEZ, Ana María. 2006. Política y Subjetividad: Asambleas barriales y fábricas recuperadas. Buenos Aires: Tinta Limón.

GARCÍA ALLEGRONE, Verónica; PARTENIO, Florencia \& FERNÁNDEZ ÁLVAREZ, María Inés. 2004. "Los procesos de recuperación de fábricas: una mirada retrospectiva". In O. Battistini (Comp.) El trabajo frente al espejo: Continuidades y rupturas en los procesos de construcción identitaria de los trabajadores. Buenos Aires: Prometeo.

GHIBAUDI, Javier. 2004. 'Um lugar para eles...' Fábricas recuperadas na Região Metropolitana de Buenos Aires (2001-2003). Dissertação de Mestrado em Planejamento Urbano e Regional. Rio de Janeiro: IPPUR/UFRJ.

GRACIA, María Amalia. 2008. Fábricas recuperadas en Argentina 2000-2006: Un campo para la invención social. Tesis de Doctorado. México: Centro de Estudios Sociológicos de El Colegio de México.

\& CAVALIERE, Sandra. 2007. “Repertorios en fábrica: La experiencia de recuperación fabril en Argentina, 2000-2006". Estudios Sociológicos XXV(73): 155-186.

GUADARRAMA OLIVERA, Rocío. 2000. “La cultura laboral”. In E. de la Garza Toledo (Coord.) Tratado Latinoamericano de Sociología del Trabajo. México: Fondo de Cultura Económica.

LEITE LOPES, José Sérgio. 1976. O Vapor do Diabo: o trabalho dos operários do açúcar. Rio de Janeiro: Paz e Terra. 1988. A tecelagem dos conflitos de classe na "Cidade das Chaminés". São Paulo/Brasília: Marco Zero/CNPq. 113-134. \& MARESCA, Sylvain. 1992. "A morte da 'alegria do povo'". Revista Brasileira de Ciências Sociais 20(7):

MAUSS, Marcel. 1979 [1923-1924]. “Ensayo sobre el don”. In Sociología y Antropología. Madrid: Tecnos.

NEIBURG, Federico. 1988. Fábrica y Villa Obrera: historia social y antropología de los obreros del cemento. Buenos Aires: Centro Editor de América Latina. 
ORTNER, Sherry. 1984. "Theory in Anthropology Since the Sixties". Comparative Studies in Society and History 26(1): 126-166.

2005. "Subjetividad, Geertz y conciencia posmoderna". Etnografías contemporáneas 1: 25-54.

OSERA. 2009. “Cantidad de Unidades Productivas Recuperadas según Jurisdicción. Argentina 2008”. In Observatorio Social de Empresas Recuperadas y Autogestión (OSERA). Buenos Aires: IIGG-UBA. Disponível in: http://www.iigg. fsoc.uba.ar/empresasrecuperadas/PDF/estadisticas.pdf. Acsesado em: 02/05/09.

PROGRAMA FACULTAD ABIERTA. 2010. Informe del Tercer Relevamiento de Empresas Recuperadas por sus trabajadores. Las empresas recuperadas en la Argentina. Buenos Aires: FFyL-UBA- Secretaría de Investigación/ Secretaría de Extensión Universitaria. Disponível em: http://www.recuperadasdoc.com.ar/Informe\%20 Relevamiento\%202010.pdf. Acesso em: 02/12/2010.

REBÓN, Julián. 2004. Desobedeciendo al desempleo. La experincia de las empresas recuperadas. Buenos Aires: Ediciones Picaso/La rosa Blindada.

2006. Trabajadores: estrategias laborales y personificaciones sociales. El proceso de recuperación de empresas. Tesis de Doctorado.. Buenos Aires: UBA-FSOC.

REYGADAS, Luis. 2002. Ensamblando culturas. Diversidad y conflicto en la globalización de la industria. Barcelona: Gedisa.

SAHLINS, Marshall. 1988 [1985]. Is/as de Historia. Barcelona: Gedisa.

1997a. “O "pessimismo sentimental" e a experiência etnográfica: por que a cultura não é um "objeto" em via de extinção (parte I)". Mana 3(1): 41-73.

1997b. “O "pessimismo sentimental" e a experiência etnográfica: por que a cultura não é um "objeto" em via de extinção (parte II)". Mana 3(2): 103-150.

SIERRA ALVAREZ, José. 1990. El obrero soñado: Ensayo sobre el paternalismo industrial (Asturias, 1860-1917). Madrid: Siglo XXI.

SIGAUD, Lygia. 1996. “Direito e coerção moral no mundo dos engenhos". Estudos Históricos 9(18): 361-388.

THOMPSON, Edward Palmer. 1989. La formación de la clase obrera en Inglaterra, Tomo / y II. Barcelona: Crítica.

VIETA, Marcelo. 2009. “Las empresas de los trabajadores: Algunos de los desafíos e innovaciones sociales de las empresas recuperadas argentinas". Congreso de la Asociación de Estudios Latinoamericanos. Río de Janeiro: LASA.

WINN, Peter. 1986. Weavers of Revolution: The Yarur Workers and Chile's Road to Socialism. New York/Oxford: Oxford University Press.

WYCZYKIER, Gabriela. 2007. De la dependencia a la autogestión laboral: Sobre la reconstrucción de experiencias colectivas de trabajo en la Argentina contemporánea. Tesis de Doctorado. Buenos Aires: FLACSO-Argentina. 
De empregados a donos. Cultura, experiência (s) e relações de alteridade no processo de tomada e recuperação de uma fábrica

\section{RESUMO}

No contexto da desestruturação social que atingiu a Argentina entre finais do século XX o início do século atual, trabalhadores de diversas empresas em crise, cuja situação laboral vinha sofrendo um processo intenso de precarização durante a década de 1990, articularam estratégias de autogestão. O fenômeno da tomada e da autogestão de empresas ocorreu diante de situações de demissões em massa, de abandono, fechamento ou falência de unidades produtivas, e converteu-se em uma das expressões sociais mais notáveis do novo milênio. No entanto, ainda que a pesquisa desse fenômeno seja significativa, até o momento não se respondeu satisfatoriamente à seguinte questão: como se constrói a idéia de que tomar e autogerir uma fábrica é uma alternativa para trabalhadores que durante anos trabalharam sob o comando de um patrão? Neste trabalho, trataremos desta questão a partir do estudo etnográfico da "cultura fabril" e das experiências de um grupo específico de operários que gerenciam uma fábrica.

PALAVRAS-CHAVE: 'cultura fabril'; experiência(s); fábrica tomada.

From employees to owners: Culture, experience(s) and otherness relations in the process of recuperation of a factory

\section{ABSTRACT}

In the context of social disruption that reached Argentina between the end of the XX century and the beginning of the present century, employees of several factories, whose labor situation was suffering an intense process of precariousness during the nineties, articulated a strategy of self management. The phenomenon of self management of factories happened after situations such as big layoffs, abandonment, closing or bankruptcy of productive unities, and it turned into one of the social expressions more noticed in the millennium. However, although the research of this phenomenon can be significant, to this moment this question has not been answered: how one builds up the idea that to self manager an industry is an alternative to employees who during years worked under the control of a patron? In this work, this question is approached from using an ethnographical study of the "factory culture" and from the experiences of a specific group of employees who have managed one factory.

KEYWORDS: "factory culture"; experience(s); "factory outlet industry".

Recebido em: $15 / 12 / 2010$

Aprovado em: 08/05/2011 